К вопросу о совершенствовании механизма регулирования внешнеэкономической деятельности Республики Узбекистан

Шохрух Б. Ахмедов

Дипломатическая академия МИД РФ, Москва, Россия

Akaxmedov20@gmail.com

Владимир М. Кутовой

Дипломатическая академия МИД РФ, Москва, Россия, kutovoy46@таil.ru

Аннотащия. В статье проанализирована внешнеторговая политика зарубежных стран и реализация таможенной политики Республики Узбекистан. Проведен анализ методов нетарифного и тарифного регулирования внешнеэкономической деятельности, а также проекты активного влияния на внешнюю торговлю страны в целях ее адаптации к требованиям мировой экономики. В ходе вступления в ВТО определены основные принципы и даны предложения мер по совершенствованию таможенно-тарифного регулирования Республики Узбекистан.

Ключевые слова: таможенные тарифы, протекционизм, Всемирная торговая организация, антидемпинговое регулирование, компенсационные меры

Для иитирования: Ахмедов Ш.Б., Кутовой В.М. К вопросу о совершенствовании механизма регулирования внешнеэкономической деятельности Республики Узбекистан // Вестник РГГУ. Серия «Экономика. Управление. Право». 2020. № 3. С. 62-71. DOI: 10.28995/2073-6304-2020-3-62-71

On the issue of improving the mechanism for regulating foreign economic activity of the Republic of Uzbekistan

Shokhrukh B. Akhmedov

Diplomatic Academy of the Ministry of Foreign Affairs of the Russian Federation Moscow, Russia, Akaxmedov20@gmail.com

\title{
Vladimir M. Kutovoi
}

Diplomatic Academy of the Ministry of Foreign Affairs of the Russian Federation Moscow, Russia, kutovoy46@mail.ru

Abstract. The article analyzed the foreign trade policy of foreign countries and the implementation of the customs policy of the Republic of Uzbekistan. The analysis of methods of non-tariff and tariff regulation of foreign economic

(C) Ахмедов Ш.Б., Кутовой В.М., 2020

ISSN 2073-6304 • RSUH/RGGU Bulletin: "Economics. Management. Law" Series, 2020, no. 3 
К вопросу о совершенствовании механизма регулирования...

activity was carried out, as well as projects of active influence on foreign trade of the country in order to adapt it to the requirements of the world economy. During the WTO accession, the main principles were defined and proposals were made for measures to improve the customs and tariff regulation of the Republic of Uzbekistan.

Keywords: customs tariffs, protectionism, World Trade Organization, antidumping, countervailing measures

For citation: Akhmedov, S.B. and Kutovoi, V.M. (2020), "On the issue of improving the mechanism for regulating foreign economic activity of the Republic of Uzbekistan", RSUH/RGGU Bulletin. "Economics. Management. Law" Series, no 3, pp. 62-71, DOI: 10.28995/2073-6304-2020-3-62-71

\section{Введение}

Государственная координация внешнеэкономической сферы реализуется, как правило, при помощи таможенного регулирования и нетарифных мер координации, к которым относятся технические стандарты и нормы лицензирования, антидемпинговые и компенсационные налоги, санитарные и ветеринарные меры и т. д.

Во всех странах сегодня растет степень воздействия на развитие конкурентоспособности страны и, соответственно, внешнеэкономическую сферу.

В государствах, ведущих либеральную финансово-политическую деятельность, правительство влияет на рынок большей частью с поддержкой таможенного тарифа (США). В прочих странах в целях адаптации к условиям мировой экономики реализуются проекты активного воздействия на хозяйственную структуру, включая стимулирование производств, способных соответствовать довольно высоким условиям новейшего мирового товарного рынка (Япония, Франция, Италия) [Кутовой, Попков 2019].

\section{Основные принципы и предложения мер по совершенствованию тарифного регулирования}

Осуществление тарифного регулирования ВЭД должно исходить из следующих основополагающих принципов [Мировая экономика 2019]:

1) оптимальное соотношение методов протекционизма и фритредерства (свободной торговли);

2) независимость тарифно-таможенного регулирования от политических взаимоотношений между государствами; 
3) обеспечение энергетической, продовольственной, технологической безопасности и самообеспеченности за счет развития ключевых отраслей экономики;

4) необходимость обеспечения занятости населения;

5) смягчение последствий экономического кризиса в стране или отдельных отраслях в случае его возникновения;

6) стимулирование конкуренции между отечественными и зарубежными производителями;

7) открытость и прозрачность таможенных пошлин и ставок;

8) осуществление политики тарифного регулирования ВЭД в увязке с проводимой промышленной политикой и с учетом реального уровня конкурентоспособности производимых товаров.

Процесс таможенно-тарифного регулирования должен осуществляться с учетом процесса либерализации в части поэтапного снижения импортных тарифов. Это означает, что необходимо постепенно снижать импортные тарифы с целью либерализации рынка и обеспечения открытости, при этом параллельно создавая условия для наращивания производственного потенциала страны и повышения конкурентоспособности отечественных товаров.

При этом важна постепенность либерализации внешней торговли. Это даст своеобразный сигнал для многих предприятий подготовиться к дальнейшим реформам. Более того, такая политика определит эффективные производства и те отрасли, где у страны имеются сравнительные преимущества. Для того чтобы временно ослабить влияние повышенной конкуренции для некоторых важных отраслей и предприятий экономики можно будет в приоритетном порядке размещать государственные заказы в эти предприятия при условии дальнейшей трансформации их производственных систем.

Необходимо устанавливать таможенные пошлины исходя из особенностей функционирования и развития смежных отраслей. Наличие высоких ставок импортных таможенных пошлин на продукцию одних отраслей может приводить к увеличению затрат и снижению конкурентоспособности других, смежных отраслей экономики. Кроме того, чрезмерно высокие пошлины на импорт ведут к более высокому уровню цен на внутреннем рынке по сравнению с ценами на внешних рынках, а это сдерживает активность отечественных производителей в поиске рыночных ниш на зарубежных рынках, тем самым препятствуя росту экспорта страны. К тому же чрезмерно высокий уровень протекционизма путем высоких импортных пошлин приводит к снижению стимулов у производителей к разработке и внедрению научно-технических разработок, повышению качества, снижению себестоимости и постоянному

ISSN 2073-6304 • RSUH/RGGU Bulletin: “Economics. Management. Law” Series, 2020, no. 3 
обновлению выпускаемой продукции. Необходимо учитывать данный аспект при осуществлении тарифного регулирования.

Целесообразным является установление сравнительно низких импортных пошлин на определенные виды сырья, полуфабрикатов, комплектующих, производство которых на территории Узбекистана не представляется возможным или имеет ограниченные возможности, но которые критически необходимы для развития производства отдельных видов продукции.

Предполагаемая возможность вступления Узбекистана в интеграционные торговые объединения ставит перед государством новые задачи, в числе которых - создание благоприятных условий для партнерских отношений с участниками внешнеэкономической деятельности (ВЭД). Таким образом, тарифно-таможенная политика должна исходить из учета потенциальных изменений в случае вступления в интеграционные объединения, а именно дальнейшее поэтапное снижение тарифных барьеров в торговле в соответствии с рекомендациями стран-членов ВТО и ЕАЭС, сближение национального законодательства с условиями этих организаций, а также проведение других необходимых реформ [Малинина 2010].

Необходимо внедрить принципиально новые подходы организации работы Республиканского совета по тарифному и нетарифному регулированию, в частности в области тарифного регулирования.

Наряду с этим улучшение и осуществление таможенной политики - непростая работа, в которой присутствуют все органы власти правительства: судебная, исполнительная и законодательная. При этом в обязательном порядке должны учитываться мнение и предложения участников ВЭД.

\section{Основные принципы и предложения мер по совершенствованию нетарифного регулирования}

Улучшение нетарифной координации внешнеторговой деятельности требует от стран комплекс мер и действий, охватывающих его гармонизацию с регламентами и порядками, сложившимися на мировом рынке, упрощения процедуры лицензирования, усовершенствования законодательной базы, повышения эффективности экологических и других защитных мер [Стрельникова, Зенкина 2015].

Зарубежный опьт. Традиция защиты странами Западной Европы своих интересов как на отечественных, так и на зарубежных рынках представляет собой симбиоз различных методов политики свободной торговли и политики протекционизма. При этом пред- 
полагается защита как отдельных производителей и потребителей, так и экономики государства в целом.

Законодательство стран Западной Европы, входящих в Европейский союз, формирует некоторые общие условия импорта товаров и услуг из третьих стран. Важно заметить, что совокупность условий импорта распространяются на требования ввоза на таможенную зону Евросоюза продуктов из государств, которые, в свою очередь, не входят в Европейский союз.

Во Франции, как и в других странах Европейского союза, в обоснованных случаях применяются нетарифные методы регулирования внешней торговли. Так, к основным таким методам во Франции относятся антидемпинговое регулирование и компенсационные меры (специальные защитные меры).

1. Антидемпинговое регулирование - среди нетарифных мер регулирования внешней торговли экономического характера важную роль во Франции играет именно антидемпинговое регулирование. Более того, Франция входит в первую десятку стран, которые лидируют по общему числу антидемпинговых расследований.

Антидемпинговые меры введены и распространяются приблизительно на 0,5\% от общего объема импорта товаров, ввозимых на таможенную территорию страны. Более того, важно отметить, что такая тенденция характерна также и для большинства стран Европейского союза.

В целом антидемпинговые меры во Франции предпринимаются относительно стран-импортеров на время, необходимое для дальнейшей нейтрализации общего воздействия демпингового импорта на промышленную отрасль Франции, но при этом указанный период не должен превышать пяти лет.

2. Компенсационные мерь - это один из инструментов нетарифного регулирования экономического характера, который, в свою очередь, применяется Францией (и другими западноевропейскими странами) с целью нейтрализации воздействия субсидирования импорта на условиях конкуренции.

Итоговая величина компенсационной пошлины формируется в зависимости от размера установления ущерба от специфических субсидий для экономики Франции. Существуют определенные процедуры организации и проведения расследования в отношении конкретной страны (группы стран), а также порядок введения компенсационной пошлины по результатам расследования.

Таким образом, можно сделать вывод, что страны Западной Европы практикуют в настоящее время применение нетарифных методов регулирования внешней торговли. Однако их реализация строго регламентирована для стран-членов ВТО. ВТО является

ISSN 2073-6304 • RSUH/RGGU Bulletin: "Economics. Management. Law" Series, 2020, no. 3 
сторонником политики именно открытой экономики с применением преимущественно тарифных методов регулирования. Нетарифные методы регулирования внешней торговли, а точнее их определенный перечень, могут применяться в строго определенных случаях и только при условии подтверждения необходимости их применения.

Япония, страны Западной Европы, а также США применяют нетарифные методы регулирования внешней торговли. Так, общая система специализированного лицензирования деятельности внешнеэкономического характера в Японии в принципе отсутствует, а непосредственно сама регистрация участников внешнеэкономической деятельности осуществляется на общих основаниях в качестве субъектов, осуществляющих предпринимательскую деятельность.

Нетарифные меры регулирования ВЭД состоят из квотирования, сертификации, валютного контроля, фитосанитарного контроля, лицензирования, ветеринарного надзора, санитарно-эпидемиологического контроля, специальных, антидемпинговых, компенсационных пошлин и др.

В послании Олий Мажлису Республики Узбекистан Президент подчеркнул:

следует улучшить систему контроля и инфраструктуры в сфере внешней торговли. В частности, на основе зарубежного опыта необходимо реформировать деятельность таможенных, санитарных, карантинных, ветеринарных и других служб, осуществляющих контроль на таможенных постах ${ }^{1}$.

В 2020 г. предусмотрено принять около 3 тысяч стандартов, довести их число до 10 тысяч, а уровень соответствия международным стандартам - до 40\%.

Совершенствованию нетарифного регулирования способствуют меры господдержки трудоемких отраслей промышленности (пищевая, текстильная, швейная, некоторые отрасли химии и нефтехимии), имеющих преимущества в международной торговле: помощь в получении сертификатов качества ISO, рассмотрение возможности снижения его стоимости; оценка возможности создания тестовых лабораторий в Узбекистане, которые сертифицированы в ЕС и/или США.

${ }^{1}$ Послание Президента Республики Узбекистан Шавката Мирзиёева Олий Мажлису - 2020 г. Ташкент [Электронный ресурс]. URL: https:// review.uz/ru/post/uzbekiston-respublikasi-prezidenti-savkat-mirzieevningolij-mazlisga-murozaatnomasi (дата обращения 20 мая 2020).

ISSN 2073-6304 • Вестник РГГУ: Серия «Экономика. Управление. Право». 2020. № 3 
В целях повышения эффективности экспортной деятельности предприятий и конкурентоспособности отечественной продукции на зарубежных рынках необходимо подготовить предложения по привлечению новых международных компаний, органов по сертификации в Республике Узбекистан, созданию современных лабораторий, центров сертификации, стандартизации и испытаний и внедрению в национальные нормативные документы новых сертификационных требований в соответствии с международными стандартами; оказанию помощи малому бизнесу и частному предпринимательству во внедрении международных стандартов качества, в получении необходимых для экспорта сертификатов, в том числе помощь в международной сертификации (HASP, Global Gap и др.) [Зенкина, Кутовой 2018].

Существующая инфраструктура не выдерживает значительно увеличившийся поток грузов, пересекающих границу. Необходимо оснастить пункты ветеринарного и карантинного контроля необходимым оборудованием. Службы санитарного и эпидемиологического надзора на границе подготовить должным образом к отражению воздействий внешних рисков.

Касательно вопросов нетарифного регулирования планируется, что будет принято решение о расширении диалога с ВТО и определению нового этапа сотрудничества и партнерства с Европейским союзом, расширения привлечения Узбекистана в других мировых и территориальных экономических объединениях.

В целом можно отметить, что таможенная система Узбекистана характеризуется наличием существенных нетарифных барьеров для импорта. Согласно рейтингу «Ведение бизнеса» время на прохождение пограничного и таможенного контроля в Узбекистане составляет 111 часов (стоимость - 278 долл. США), а время на оформление документов составляет 150 часов (стоимость - 242 долл. США), что намного выше показателя стран Европы и Центральной Азии ${ }^{2}$.

Согласно отчетам ESCAP, уровень расходов при торговле с Узбекистаном намного превышает уровень при торговле с ЕС и Восточноазиатскими странами.

Изучение тенденций на внешних рынках показывает, что наличие договоров о преференциальной торговле значительно влияет на объемы экспорта. Например, благодаря таким соглашениям (как

${ }^{2}$ Economy Profile of Uzbekistan Doing Business 2020 Indicators (in order of appearance in the document) [Электронный pecypc]. URL: https://www. doingbusiness.org/content/dam/doingBusiness/country/u/uzbekistan/UZB. pdf (дата обращения 12 апр. 2020).

ISSN 2073-6304 • RSUH/RGGU Bulletin: "Economics. Management. Law" Series, 2020, no. 3 
EBA, GSP, GSP+) такие страны, как Бангладеш, Вьетнам, Индия, Камбоджа, смогли значительно улучшить свои позиции на мировом рынке текстиля и одежды. Анализы показывают, что основные объемы экспорта текстиля и одежды Узбекистана направляются именно в страны, с которыми у нас имеются договоры о преференциальной торговле. Таким образом, расширение преференций с основными мировыми импортерами узбекской продукции позволит значительно улучшить конкурентные позиции Узбекистана на мировом рынке.

\section{Приниипы дальнейшего совершенствования таможенно-тарифного регулирования в Республике Узбекистан}

Для того чтобы усовершенствовать таможенно-тарифное регулирование, требуется применить нижеследующие принципы. В частности:

- регулярно совершенствовать механизмы тарифного регулирования внешнеторговой деятельности с учетом передового международного опыта, правил и норм Всемирной торговой организации с целью уравнивания рисков и отрицательных воздействий для экономики государств;

- сохранить предоставление благоприятных условий для ввозимого технологического оборудования и техники для того, чтобы интенсифицировать дальнейший процесс модернизации и перевооружения национального производства, который ускорит реализацию инфраструктурных проектов;

- создать условия для обеспечения отечественных производителей сырьевыми материалами, которые не производятся в республике Узбекистан или же производятся в недостаточном объеме и используются в выпуске экспорт ориентированных товаров;

- для того чтобы развивать внутреннее производство, применить принципы тарифной эскалации на готовую продукцию, которые содействуют реальному росту конкурентоспособности национальных товаров [Navrotskaia, Kovaleva 2018].

Самым важным фактором укрепления геополитических позиций государства и географической диверсификации ее внешнеторговой деятельности является включение Узбекистана в мировую транспортную систему, которая основана на формировании соответствующей инфраструктуры и улучшении мультимодальных транспортных коридоров; 
- внедрить практику использования сезонных налогов. Рекомендуется внедрить снижение импортных тарифов на быстропортящиеся фрукты, производимые в Узбекистане, но не плодоносящие в осенне-зимний период, на период с 1 октября до 1 марта.

Предложенные рекомендации, по нашему мнению, будут способствовать совершенствованию таможенно-тарифного регулирования Республики Узбекистан.

\section{Лuтература}

Зенкина, Кутовой 2018 - Зенкина Е.В., Кутовой В.М. Торговля и мир: политическая расстановка сил обусловлена экономической взаимосвязью // Вестник университета. 2018. № 10. С. 93-97.

Кутовой, Попков 2019 - Кутовой В.М., Попков Ю.В. К вопросу о важности инновационно-технологического фактора в устойчивом развитии экономической системы // Вестник РГГУ. Серия «Экономика. Управление. Право». 2019. № 3. C. 94-105.

Малинина 2010 - Малинина E.B. Совершенствование механизма защиты национальных интересов в финансовой сфере // Вестник РГГУ. Серия «Экономика. Управление. Право». 2010. № 6 (49). С. 31-40.

Мировая экономика 2019 - Мировая экономика: Учеб. / Щербанин Ю.А., Зенкина Е.В., Толмачев П.И., Грибанич В.М., Дрыночкин А.В., Королев Е.В., Кутовой В.М., Логинов Б.Б. 5-е изд., перераб. и доп. М.: Юнити-Дана, 2019. 503 с.

Стрельникова, Зенкина 2015 - Стрельникова Е.В., Зенкина Е.В. Упрощение процедур торговли в условиях современной мировой экономики // Известия Московского государственного технического университета МАМИ. 2015. Т. 5. № 3 (25). C. 57-60.

Navrotskaia, Kovaleva 2018 - Navrotskaia N.A., Kovaleva E.A., Kutlyeva G.M., Bogacheva T.V., Zenkina E.V., Bondarchuk N.V. Technological cooperation trends under conditions of the modern world economy // International Journal of Engineering and Technology (UAE). 2018. T. 7. № 3.15 Special Issue 15. C. 288-292.

\section{References}

Kutovoi, V.M. and Popkov, Yu.V. (2019), "On the importance of the innovative technology factor in sustainable development of an economic system”, $R S U H / R G G U$ Bulletin. "Economics. Management. Law” Series, no 3, pp. 94-105.

Malinina, E.V. (2010), "Enhancing the system of the national interests protection in financial sphere”, RSUH/RGGU Bulletin. "Economics. Management. Law” Series, no 6 (49), pp. 31-40.

Navrotskaia, N.A., Kovaleva, E.A., Kutlyeva, G.M., Bogacheva, T.V., Zenkina, E.V. and Bondarchuk, N.V. (2018), Technological cooperation trends under conditions of the modern world economy, International Journal of Engineering and Technology(UAE), T. 7, no 3.15, Special Issue 15, pp. 288-292. 
Strelnikova, E.V. and Zenkina, E.V. (2015), "Trade facilitation in modern global economy”, Izvestiya Moskovskogo gosudarstvennogo tekhnicheskogo universiteta MAMI, vol. 5, no 3 (25), pp. 57-60.

Shcherbanin, Yu.A., Zenkina, E.V., Tolmachev, P.I., Gribanich, V.M., Drynochkin, A.V., Korolev, E.V., Kutovoi, V.M. and Loginov, B.B. (2019), Mirovaya ekonomika, Uchebnik [World Economy. Textbook], Yuniti- Dana, Moscow, Russia.

Zenkina, E.V. and Kutovoi, V.M. (2018), "Trade and peace. Political alignment of forces is defined by economic interconnection", Vestnik universiteta, no 10, pp. 93-97.

\section{Информация об авторах}

Шохрух Б. Ахмедов, аспирант, Дипломатическая академия МИД РФ, Москва, Россия; 119021, Москва, ул. Остоженка, д. 53/2, стр. 1; Akaxmedov20@gmail.com

Владимир М. Кутовой, доктор экономических наук, профессор, Дипломатическая академия МИД РФ, Москва, Россия; 119021, Москва, ул. Остоженка, д. 53/2, стр. 1; kutovoy46@mail.ru

\section{Information about the authors}

Shokhrukh B. Akhmedov, post-graduate student, Diplomatic Academy of the Ministry of Foreign Affairs of the Russian Federation, Moscow, Russia; bldg. 1, bld. 53/2, Ostozhenka Str., Moscow, Russia, 119021; Akaxmedov20@gmail.com

Vladimir M. Kutovoi, Dr. of Sci. (Economics), professor, Diplomatic Academy of the Ministry of Foreign Affairs of the Russian Federation, Moscow, Russia; bldg. 1, bld. 53/2, Ostozhenka Str., Moscow, Russia, 119021; kutovoy46@mail.ru 